\title{
ЕДИНАЯ РАБОЧАЯ ГИПОТЕЗА ЭТИОЛОГИИ И ПАТОГЕНЕЗА ОПУХОЛЕИ
}

\author{
П. А. Боговский, \\ кандидат меднцинскнх наук
}

Проблема рака (злокачественных опухолей) является в настоящее время одной из наиболее актуальных проблем медицины и биологии. Заболеваемость раком нарастает по всему миру (А. Н. Сысин, Л. А. Зильбер, В. А. Рязанов, Л. М. Шабад, 1956). Е США рак был в 1900 г. на восьмом месте среди причин смерти (4\% умерших), а в 1953 г. на втором месте (15\% умерших) (G. Nelson, 1955). В США за последние 5 лет смертность от рака составляет 139,8-146,5 на 100000 населения, в СССР соответственно 92,8-113,7 (В. М. Ждансв, 1958). Н. Н. Петров (1958) считает, что на нашей планете ежегодно умирает от рака свыше 2 млн. человек и что на земле живет свыше 5 млн. людей, больных злокачественными опухолями. Особенно частым стал рак легких, на что указывают многочисленные авторы (W. Hueper, 1957; Р. Долл, 1957; Н. Н. Петров, 1958 и др.). Резко возросла частота рака легких в Англии и Уэлсе - с 12,9 на 100000 населения в 1930-1932 гг. до 61,4 в 1952 г. (W. Hueper, 1957).

Окончательного решения проблемы рака нельзя ожидать от дальнейшего усовершенствования современных методов диагностики и лечения. Рентгено-радиологическое и хирургическое лечение, доведенное уже сейчас до высокой степени эффективности, а также медикаментозное лечение, в значительной степени эмпирическое и поэтому дающее случайные успехи, не могут обеспечить решительной ликвидации злокачественных опухолей. Окончательный успех может быть достигнут в результате выяснения этиологии и патогенеза опухолей. Это даст возможность проводить действенную профилактику путем устранения причин опухолей и разработать диагностические методы и способы лечения, применяемые на ранних стадиях развития опухолей.

Для плодотворного научного исследования проблемы рака первостепенное значение имеет объясняющая все зарегистрированные факты единая правильная теория, могущая объединить усилия исследователей, работающих в различных направлениях.

В настоящее время, однако, такая единая теория из-за недостаточности фактического материала отсутствует, несмотря на наличие многих тысяч исследований, проведенных по этиологии и патогенезу рака. Это объясняется в первую очередь чрезвычайной сложностью проблемы, так как при раскрытии закономерностей опухолевого роста мы подходим к самым сокровенным и неизученным процессам биохимизма живой материи, наследственности и изменчивости, к границам между химической молекулой и живым организмом, между веществом и существом. Бесспорно, что решение этих вопросов будет найдено только в результате совместных глубоких понсков медиков, биологов, физиков и химиков. Необходимость такого комплексного подхода к решению разных проблем была отчетливо подчеркнута на XXI съезде КПСС; она должна стать руководящим принципом организации исследований по проблеме рака.

Нет оснований ожидать разработки совершенно новой теорин, так как значительная часть обобщений существующего фактического материала войдет в будущую теорию опухолевого роста. 
Из выдвигавшихся теорий в современных условиях заслуживают внимания мутащионная, полиэтиологическая, вирусная и биохимическая. Необходимо подчеркнуть, что эти теории неравнозначны по своему охвату и содержанию, в связи с чем их невозможно сопоставлять на одном уровне. Можно выделить две основных группы этиологических концепций: полиэтиологическую теорию и моноэтиологическую, т. е. вирусную теорию. Первая признает множественность внешних причин опухолей, вторая рассматривает как причину -пухолей экзогенный убиквитарный вирус, попадающий в организм извне на какой-либо стадии его развития и вызывающий опухоль при вспомогательном действии ускоряющих, провоцирующих или разрешающих факторов (канцерогенных агентов) (Л. А. Зильбер, 1954, 1956, 1958; А. Д. Тимофеевский, 1954; У. Стенли, 1958; Л. Дмоховский, 1955; Ш. Оберлен, М. Герен, 1956 и др.).

Сторонники множественности причин опухолей подразделяются на две группы в соответствии с тем, как они рассматривают ближайшую причину и механизм опухолевого превращения клетки, приводящего к бесконтрольному росту. Одни считают, что под влиянием внешних воздействий в хромозомах клетки происходят внезапные и необратимые мутации (подобно мутациям в понятии автогенетиков), приводящие к возникновению злокачественной опухоли. Другие придерживаются убеждения, что в клетке происходят постепенные биохимические изменения ее компонентов. Мутационная теория (K. Bauer, 1949) не может объяснить ряда фактов, в том числе предшествующих злокачественной стадии опухолевых изменений и наблюдаемого, как правило, длительного скрытого периода между окончанием действия канцерогенного агента из внешней среды и появлением опухоли. Варианты мутационной теории, по которой мутируют не хромозомы, а цитоплазматические наследственные частицы (H. Nothdurft, 1948; Н. Druckrey, 1954 и др.), также не меняют сущности теории, так как момент внезапности и выдвинутый К. Бауером принцип «все или ничего» остаются в силе. Фактические данные заставили в последние годы значительно видоизменить мутационную теорию. Так, Ф. Бернет (F. M. Burnet, 1957) считает, что в основе опухолевого превращения клеток лежит соматическая мутация в широком смысле (изменение наследственности), причем имеет место многоступенчатое прогрессирующее (постепенное) изменение наследственных свойств под влиянием внешних факторов. В таком же смысле высказывается Ф. Зелих (F. Seelich, 1956), который полагает, что различные канцерогенные агенты могут обусловить изменение наследственных систем в клетке, причем это изменение может происходить постепенно и медленно или быстро, например, при внедрении в клетку чужеродной (опухолевой) нуклеиновой кислоты, действующей как трансформирующий агент.

Такие варианты мутационной теории приближают ее, по существу, к биохимической теории, рассматривающей опухолевое превращение клетки как результат постепенных биохимических (обменных, энзиматических и т. п.) изменений нормальных компонентов клетки (Л. М. Шабад, 1947; Б. И. Збарский, 1947; Н. Н. Петров, 1958; И. М. Нейман, 1958 и др.). Следует безусловно согласиться с Н. Н. Петровым (1958), отвергающим автогенетический термин «мутация» и предлагающим заменить его обозначением «опухолеродное превращение».

Подавляющее большинство видных онкологов (патологов, биохимиков, клиницистов и 2 д.) убеждено, что первопричиной опухолей являются множественные факторы внешней среды (Н. Н. Петров, 1954, 1958; Л. М. Шабад, 1947; И. М. Нейман, 1958; W. Hueper, 1957; A. Haddow, 1957; F. M. Burnet, 1957; W. Fischer, 1956; G. Domagk, 1956; A. Graffi, 1954, 1956; И. Беренблюм, 1956; F. Büchner, 1956; P. Steiner, 1953; A. Butenandt и Н. Dannenberg, 1956; F. Schmidt, 1953, 1956 и многие другие).

Большинство названных авторов рассматривает опухолевые вирусы как один из факторов внешней среды, действующий наравне с другими агентами (физическими и химическими). Часть авторов допускает, однако, с различной степенью вероятности возможность эндогенного (цитоплазматического), происхождения опухолевого вирусоподобного агента (Н. Н. Петров, 1958; Л. М. Шабад, 1947; И. М. Нейман, 1958; А. Граффи, 1956; Ф. Бюхнер, 1956; Ф. Шмидт, 1956 и ряд других). 
Именно этот вопрос - является ли опухолевый вирус чужеродным (экзогенным) инфекционным живым организмом или химическим соединением, превратившимся в вирусоподобный агент, в ряде случаев отделимый от клетки, - и является предметом разногласий между двумя господствующими теоретическими течениями в онкологии, которые, по примеру Н. Н. Петрова (1958), можно рассматривать как инфекционную и трансформационную точки зрения.

Можно отметить, что такие наиболее категоричные сторонники вирусной теории, как Л. А. Зильбер и А. Д. Тимофеевский, также видят всю суть разногласий именно в этом вопросе. Так, А. Д. Тимофеевский (1954) прямо пишет: «Особенно важное значение для разрешения проблемы опухолевого роста имеет выяснение вопроса о происхождении опухолеродных вирусов - эндогенном или экзогенном. Если встать на точку зрения, что опухолеродные вирусы возникают эндогенно, под влиянием канцерогенов, тогда вирусное учение происхождения опухолей теряет свое значение и делается лишь вариантом химической теорни».

Различные точки зрения отечественных онкологов были предметом дискуссии уже на I Всесоюзной онкологической конференции в 1947 г., а в дальнейшем на X сессии общего собрания АМН СССР 19-24 марта 1956 г. (Е. Е. Погосянц, 1956) и в не меньшей степени на II Всесоюзной онкологической конференции в Ленинграде $27-31$ января 1958 г. (М. А. Преснов и др., 1958).

По-видимому, однако, нет оснований для резкого противопоставления вирусной теории другим точкам зрения, о чем свидетельствуют также весьма осторожные и предположительные допущения, которые можно найти у таких крупных сторонников вирусной теории, как У. Стенли $(1957,1958)$, Ш. Оберлен и М. Герен $(1956)$ и др.

Нам представляется, что вирусная концепция не потеряла бы ничего, кроме ряда неясностей и нечетко формулируемых предположений, если стать на точку зрения, что под воздействием различных причин внешней среды из нормальных составных частей клетки возникают белковые комплексы типа нуклеопротеидов, обретающие в известных условиях на определенных этапах развития свойства, напоминающие некоторые особенности вирусов.

Предлагаемые нами обобщения не претендуют на оригинальность, так как основные положения их излагались уже в трудах Л. М. Шабада (1947), Н. Н. Петрова $(1954,1958)$, И. M. Неймана (1958), Р. Уиллиса (R. Willis, 1953) и др. Схожие во многом мысли опубликованы также Ф. Шмидтом (1953, 1956), Ф. Зелихом (1957) и діругими авторами. Мы произвели попытку свести в единую систему основные данные об этиологии и патогенезе опухолей, учитывая при этом, что ряд предположений еще нє доказан. Такая полиэтиологически-биохимическая рабочая гипотеза, подлежащая, несомненно, дискуссии и могущая вызвать возражения главным образом среди сторонников вирусной теории, может, однако, уже в настоящем виде дать некоторые направления для дальнейших планомерных научных исследований по проблеме рака.

\section{І. Этиология}

Рассматривая этиологию опухолей, необходимо учесть, что невозможно и методически неправильно противопоставлять причинные факторы внешней среды, составляющие предмет этиологии, и ответные реакции организма на эти внешние факторы, являющиеся содержанием патогенеза заболевания, так как одни внешние факторы сами по себе не могут служить причиной болезни - ее можно понимать лишь во взаимодействии внешних факторов и организма. Поэтому учение о внешних факторах, т. е. этнологию, невозможно отделить от учения о процессах, возникающих в организме, о фнзиологических механизмах возникновения, развития и ликвидации заболевания, т. е. от патогеяеза. Вместе с тем неправильно было бы, как это подчеркивает И. В. Давыдовский (1956), исходя из принципа единства внешней и внутренней среды, произвести слияние понятий этиологии и патогенеза. Наоборот, их следует четко разграничивать, чтобы глубже понять их взаимопроникновение. 
Сказанное полностью относится и к проблеме опухолей, поэтому с целью более глубокого аналитического подхода мы будем рассматривать этиологию и патогенез опухолей раздельно.

В настоящее время не все причинные факторы опухолей изучены. В этой связи следует в первую очередь определить наше отношение к вопросу о наследственных опухолях. И. В. Давыдовский (1956, стр. 16-17) считает наследственные заболевания вызванными внешними факторами, «поскольку передача по наследству предрасполагающих к той или иной болезни физиологических факторов предполагает наследование их как приобретенных признаков», и указывает, что представление о внешней среде не следует понимать упрощенно, как о среде, окружающей организм в ходе его нндивидуального развития. Вопрос наследственности опухолей был предметом многочнсленных исследований, но, как видно из последних сводок Н. Н. Петрова и Л. М. Шабада (1958), В. Фишера (W. Fischer, 1956), Л. Лоу (L. Low, 1956) и др., окончательно он еще не разрешен. Наиболее правильной является разделяемая большинством авторов точка зрения, что наследуется не сама опухоль, а предрасположение (общее или органное) к возникновению опухоли под влиянием различных факторов. По-видимому, те же внешние факторы вызывают закономерно одинаковые опухоли на фоне наследуемых предрасполагающих изменений.

Большой интерес представляют опыты Л. М. Шабада (1947), в которых удалось доказать, что у потомства мышей, смазывавшихся канцерогенной смолой, под влиянием этого же агента отдаленные опухоли (аденомы легких) возникали значительно чаще, чем у контрольных. Л. Стронг получил аналогичные результаты, вызывая у последующих поколений мышей опухоли желудка при помощи метилхолантрена (Л. М. Шабад, 1947). Он показал, что путем отбора и скрещивания можно вывести линию мышей, у которой опухоли желудка часто возникают даже без применения метилхолантрена. В свете этих данных следует рассматривать и так называемые чнстые линии мышей, у которых с определенной частотой возникают спонтанные опухоли или которые имеют піаеледуемые особенности восприимчивости к индуцированным опухолям.

Не подлежит сомнению необычайное многообразие опухолей, которые в то же время, как указывает М. Ф. Глазунов (1958), могут быть классифицированы по различным признакам (по эмбриогенетическому, гистологическому, клиническому, онконозологическому принципу), причем основным критернем является морфология опухолевой ткани. Это приводит к заключению, что и причины опухолей должны быть различными. В одних случаях (рак кожи, рак легких и т. д.) легче проследить причинноследственную связь между экзогенным фактором и опухолью, хотя и здесь о непосредственном действии можно говорить только условно, так как в любом случае имеет место взаимодействие с организмом. В других случаях, когда экзогенные причины опосредуются организмом путем более сложных механизмов, чаще всего невыясненных, причинно-следственная связь не может быть легко обнаружена. Важно подчеркнуть, однако, что и в таких случаях следует искать экзогенные причины опухолей. То же относится и к наследованию предрасполагающих факторов. Так называемые эндогенные канцерогенные вещества (Л. М. Шабад, 1947, 1958) являются также результатом опосредования внешних причин. В последнее время высказывается мнение (E. Kennaway, 1957), что таким эндогенным канцерогенным фактором является холестерин, вокруг скоплений которого в тканях наблюдается развитие опухолей. Гормоны рассматриваются некоторыми авторами (В. Гарднер, 1955) как канцерогены, возникающие эндогенно и действующие на расстоянии (не местно). Вместе с тем В. Гарднер в ваключении обзора, составленного на основании 362 работ, допускает возможность, что «ни гормон, ни продукты его обмена не являются канцерогенными веществами». Во всех случаях причины гормональных сдвигов следует искать во внешней среде, без изменений в которой невозможно представить себе сдвиги в гормональном балансе организма. Также и другие возможные эндогенные опухолеродные факторы (различные метаболиты) не могут возникнуть без внешних причин.

В настоящее время твердо установлено существование ряда канцерогенных факторов внешней среды, закономерно вызывающих опухоли при воздействии на организм. 
Начиная с первых наблюдений Персиваля Потта в 1775 г. о причинной связи рака трубочистов с каменноугольной сажей, накоплено много данных о профессиональных опухолях, вызываемых у людей различными агентами главным образом фнзической и химической природы. Химических веществ, вызывающих опухоли у людей, сравнительно немного: по последней сводке В. Хюпера (W. Hueper, 1957), бесспорно канцерогенными для человека химическими веществами являются следующие:

1. Неорганические вещества: мышьяк, асбест, бериллий, хром, железо, никель.

2. Органическ̇ие соединения: a) ароматические полициклические соединения: бензол, ароматические амины и азосоединения; каменноугольные смола, пек, асфальт, сажа, антраценовое и креозотовое масла; растительный деготь, древесный и табачный деготь, древесная сажа, сланцевые и буроугольные масла и смолы; нефтяные парафин, масла, смолы, пек, асфальт, растворители, са́жа, продукты сгорания; б) алифатические углеводороды: изопропиловое масло, иприт (горчичный газ).

В опытах на животных подтверждено канцерогенное действие всех перечисленных веществ, хотя действне их на различные виды животных различно. Так, бета-нафтиламином, вызывающим опухоли мочевого пузыря у человека, удалось такие же опухоли вызвать только у собаки. На животных изучено канцерогенное действие значительного количества различных химических соединений. Так, Дж. Хартуелл приводит данные о 1329 соединениях, испытанных до 1947 г., из которых канцерогенными оказались 323 (R. Willis, 1953). Следует, однако, подчеркнуть, что далеко не все данные, собранные Хартуеллом из разных источников, одинаково убедительны. Бесспорных химических канцерогенных соединений, вероятно, не больше нескольких десятков.

Физические канцерогенные факторы, так же как и химические, были сначала установлены на основании человеческой патологии и в дальнейшем проверены в опытах на животных. Бесспорно установлено опухолеродное действие ультрафиолетовых лучей с длиной волны ниже $3340 \AA$ (наиболее активная область около $2900 \AA$ ) (Н. Н. Петров, 1958; A. Butenandt и Н. Dannenberg, 1956 и др.). Рак кожи, вызванный рентгеновскими лучами, был описан вскоре после их открытия. Бесспорно доказано возникновение рака легких у шнееберговских и яхимовских горняков от воздействия дочерних продуктов радона (Ф. Л. Лейтес, 1958). Известны случаи опухолей у человека от радиоактивного контрастного вещества - торотраста (двуокись тория) и т. д. Большой интерес представляют проведенные Н. Н. Петровым с сотрудниками $(1956,1958)$ опыты на обезьянах, показавшие опухолеродное действие радиоактивных веществ.

Особое внимание следует, по нашему мнению, обратить на космические лучи как на вероятный причинный фактор опухолей. К. Бауер (К. Bauer, 1949) приводит данные опытов, доказавших, что у низкораковых мышей при интенсивном вторичном космическом излучении возникает большое количество спонтанных опухолей и, наоборот, у высокораковых мышей при изоляции от действия таких лучей частота спонтанных опухолей резко снижается. Предположение К. Бауера о том, что сильно проникающие космические лучи играют причинную роль в возникновении сарком глубоко лежащих тканей, подтверждает в последнее время Ю. Кэрблер (J. Körbler, 1957), отмечая связь частоты сарком у пожилых людей с максимумами ливней космических лучей в зимнее время.

В качестве третьего вида экзогенных причин возникновения опухолей большинством авторов рассматриваются биологические факторы. Так, В. Хюпер (W. Hueper, 1957) указывает в качестве причины рака мочевого пузыря у полевых рабочнх долины Нила бильгарцию (Schistosomum haematobium). Н. Н. Петров (1958) приводит данные экспериментов на крысах, у которых во внутренних органах рядом с цистицерками кошачьего лентеца (Taenia crassicollis) развиваются саркомы, считая, что наиболее вероятной является зависимость этих опухолей от химических продуктов, выделяемых цистицерками. Возможно, что и бильгарции действуют таким же образом. Среди биологических канцерогенных агентов особое место занимают опухолевые вирусоподобные агенты, являющиеся субстратом прививки опухолей бесклеточными фильтратами.

Исходя из факта, что имеются различные химические канцерогенные соединения, сторонники вирусной теории (Л. А. Зильбер, 1956; А. Д. Тимофеевский, 1954) припи- 
сывают канцерогенным агентам роль неспецифических факторов, вызывающих местную тканевую пролиферацию и тем самым способствующих проявлению опухолеродного действия вируса. Имеются, однако, многочисленные химические соединения, в том числе кислоты, щелочи, соли тяжелых металлов, органические и другие соединения, вызывающие раздражение и повреждение клеток с последующей местной пролиферацией, но никогда не приводящие к возникновению опухоли.

Проведенные в нашем институте * исследования (Х. К. Туру) указывают на вначительное различие в действии неканцерогенных сланцевых фенолов по сравнению с канцерогенными составными частями сланцевых смол, хотя обе группы веществ вызывают повреждение клеток и пролиферативную реакцию. Более того, следует особо подчеркнуть общеизвестный факт, что небольшое изменение химической структуры канцерогенного соединения резко изменяет его опухолеродную активность, вплоть до полной ее утраты (Л. М. Шабад, 1947), Убедительные данные об этом приводятся на основании обширного материала в сводке Г. Беджера (1956); А. Бутенандт и Г. Данненберг (A. Butenandt, Н. Dannenberg, 1956) указывают, например, что все 15 возможных пентациклических ароматических углеводородов изучены в отношении их канцерогенной активности и лишь 5 из них оказались активными в разной степени, причем сильно канцерогенными являются только $1,2,5,6$-дибензантрацен и 3,4-бензпирен, а, например, 1, 2, 7, 8-дибензантрацен обладает слабым канцерогенным действием. Это доказывает, что даже небольшое изменение расположения бензильных групп в молекуле соединения изменяет его канцерогенную активность. При введении в молекулу слабо канцерогенного 1,2-бензантрацена двух метиловых групп получается очень сильно канцерогенное соединение 9, 10-диметил-1,2-бензантрацен и т. д. Эти факты привлекают в последние годы возрастающее внимание ученых, пытающихся объяснить сущность этих закономерностей. Так, М. Аркос и И. Аркос (M. Arcos, J. Arcos, 1958) выявияли, что при канцерогенезе играют значительно большую роль, чем предполагается, стереохимические аспекты. А. Пульман и Б. Пульман (1957) выдвинули на основании многочисленных экспериментов теорию о зависимости канцерогенной активности от густоты $\pi$-электронов в соответствующих активных участках (К-областях) молекулы ароматического углеводорода. Существенными в этом направлении являются также работы А. Лакассаня с соавторами (1958). Эти данные, бесспорно, свидетельствуют об определенной специфичности канцерогенных агентов. С другой стороны, известно, что ряд канцерогенных соединений обладает отчетливой видоспецифичностью. Например, 3,4-бензпирен, вызывающий закономерно (до $100 \%$ случаев) рак кожи при смазывании мышей, оказывается неактивным при нанесенни его на кожу крысы. А. Бутенандт и Г. Данненберг (A. Butenandt, Н. Dannenberg, 1956) указывают, что до сих пор не удалось еще вызвать опухолей ароматическими полициклическими углеводородами у собаки и обезъяны. Установлено также, что разные инбредные линии мышей обладают различной чувствительностью к канцерогенным соединениям (И. Беренблюм, 1956 и др.). Вместе с тем известно, что одно и то же соединение может вызвать как одинаковые, так и разные опухоли у различных видов животных и в различных тканях одного и того же животного. Поэтому можно говорить лишь об относительной специфичности канцерогенных соединений (Л. М. Шабад, 1947). Против представления о ведущем значении местного раздражающего действия в генезе экспериментального рака говорят также так называемые отдаленные опухоли, возникающие во внутренних органах при накожном применении канцерогена, например аденомы легких при смазывании кожи каменноугольной смолой (Л. М. Шабад, 1947) или сланцевым котельным топливом (П. А. Боговский, 1954). В опытах Л. А. Грицюте (1956) внутрибрюшинно вводился уретан, в результате чего возникали аденомы легких в четкой зависимости от применявшейся дозы. Зависимость времени появления и частоты возникающих при действии канцерогенного соединения опухолей от дозы установлена многочисленными экспериментами (см. И. Беренблюм, 1956).

* Институт экспериментальной и клинической медицины АН ЭССР. 
Кроме того, имеются отчетливые данные о повышении частоты профессиональных опухолей с удлинением стажа работы (R. Fisher, 1953 и др.), что также зависит от увеличения суммарной дозы канцерогенного агента.

В экспериментах на животных установлено явление так называемого коканцерогенного действия различных неканцерогенных раздражающих факторов. В обзоре И. Беренблюма (1956) приведен обширный фактический материал многочисленных исследователей, свидетельствующий об ускоряющем, усиливающем или разрешающем влиянии различных химических веществ и травмы при воздействии канщерогенных агентов. Существуют также вещества, действующие антиканцерогенно, подавляя возникновение опухолей, вызываемых канцерогенными агентами. Ряд веществ потенцирует действие канцерогенных агентов. Так, А. Хортон, Д. Денман и Р. Троссет (А. Horton, D. Denman, R. Trosset, 1957) установили потенцирующее действие алифатических углеводородов; нами было установлено потенцирующее действие медицинского вазелина, состоящего из парафиновых углеводородов с высокой точкой плавления, при смазывании кожи мышей разными разведениями сланцевой камерной смолы.

Эти экспериментальные данные имеют большое значение и для человеческой патологии. Нет сомнений, что комбннации различных канцерогенных агентов, даже в весьма малых дозах, с определенными неканцерогенными раздражающими факторами могут иметь большое значение при возникновении рака у человека. Ряд авторов (F. Burnet, 1957; E. Kennaway, 1957; W. Hueper, 1957) подчеркивает значение комбинированного действия различных канцерогенных агентов, причем особенно выделяется значение для человека слабых канцерогенных факторов (Е. Kennaway, 1955; P. Kotin, 1958 и др.).

В свете данных о коканцерогенном и потенцирующем действии следует, по нашему мнению, понимать и так называемые бытовые раки и роль травмы в возникновении рака у человека. Большое внимание уделяется пищевому фактору в генезе рака пищевода и желудка. Л. Ф. Ларионов (1955) указывает, например, что рак пищевода составляет в прибалтийских республиках $2,5 \%$ всех опухолей, а в Якутской АССР свыше $20 \%$, и отмечает, что едва ли можно сомневаться в том, что питание мерзлой рыбой и питье очень горячего чая играют при этом свою роль. В. Фишер (W. Fischer, 1956) связывает повышенную частоту рака желудка в отдельных странах с обильным потреблением жирной пищи. На возможное слабое канцерогенное действие холестерина, поступающего с пищей, указывает также Э. Кеннауей (Е. Kennaway, 1957). Р. Уиллис (R. Willis, 1953) рассматривает травму как фактор, вызывающий опухоль в тканях, подготовленных канцерогенами. По-видимому, именно комбинированное действие разных (канцерогенных и неканцерогенных) агентов является причиной большинства (если не всех) опухолей человека. Об этом в настоящее время имеется еще мало данных, которые могут быть получены в результате длительных целенаправленных исследований, особенно в области географической патологии рака и статистики.

По нашему мнению, заслуживает особого внимания совместное действие пищевых факторов и травмы с такими канцерогенными агентами, как ультрафиолетовые лучи, космическое и радиоактивное излучение.

Возможно, что именно эти факторы являются причиной большинства опухолей, которые сейчас расцениваются как жспонтанныеж и о которых Л. А. Знльбер (1956) говорит, что они «возникают естественным путем, а не в результате какого-либо определенного воздействия».

Одним из наиболее веских доказательств этиологического значения различных факторов внешней среды служит успешная ликвидация определенных видов опухолей в результате устранения причинного фактора. Профессиональный рак рентгенологов, встречавшийся часто в начале столетия, в настоящее время в результате применения защиты от лучей практически ликвидирован (Н. Н. Петров, 1958). Рак мошонки, поражавший в Англии в XIX столетин вначительную часть трубочистов, теперь встречается крайне редко (J. Brown, J. Thornton, 1957). Частота рака кожи в шотландской сланцевой промышленности резко снизилась после внедрения комплекса профилактических мероприятий (W. Smith, 1952). 
В патологии известно, что большинство типичных опухолей различных органов человека имеют характерные гистологические особенности, установленные уже давно.

Описания авторов прошлого века, как правило, вполне соответствуют современным представлениям и являются основой гистологической диагностики опухолей. По-видимому, причины опухолей весьма константны и не могут подвергаться биологической изменчивости, как это установлено относительно возбудителей инфекционных заболеваний (Н. Н. Жуков-Вережников, И. Н. Майский и Л. А. Калиниченко, 1955; П1. Ф. Здродовский, 1959 и.др.). Это говорит о том, что эти причины не являются живыми существами - инфекционными организмами. И действительно, какие-либо доказательства заразности опухолей отсутствуют (Н. Н. Петров, 1958). Нет сведений также и об эпидемических вспышках или природной очаговости и движении опухолей согласно законам эпидемиологии. Тем более не имеется данных об эффективности противоэпидемических мероприятий в борьбе против рака, тогда как положительное значение мер профилактики, устраняющих причины опухолей, доказано практикой.

В связи со сказанным невозможно согласиться с мнением Л. А. Зильбера (1958, 1959) (являющимся логическим результатом его концепции об экзогенно-вирусной этиологии опухолей) о том, что следует начать изучение эпидемиологии опухолей человека. С другой стороны, исследования последних лет по распространению рака легких в разных странах, приведенные в сводке Р. Долла (1957), доказывают, что плоскоклеточный и мелкоклеточный рак легких, частота которого возросла у мужчин, обусловлен распространением курения и развитием промышленности и автотранспорта. В. Хюпер (W. Hueper, 1957) приводит яркие данные, показывающие зависимость частоты рака легких от величины города и концентрации в нем промышленности. Показано также, что в деревнях рак легких встречается значительно реже, чем в городах. Такая фочаговость» отчетливо зависит от экзогенных факторов, в основном уже изученных и не имеющих ничего общего с ннфекционными агентами.

Многочисленные опыты на животных, начиная с экспериментов К. Ямагива и K. Ичикава (К. Yamagiwa, К. Itchikawa, 1917), доказывают, что факторы, вызывающие профессиональные опухоли, закономерно вызывают такие же опухоли у подопытных животных. Обратная закономерность, однако, не во всех случаях доказана, в частности это касается чистых канцерогенных соединений, тогда как комплексные смеси (смолы, смазочные масла и др.) действуют, как правило, на человека так же канцерогенно, как и на подопытных животных, особенно если основываться на испытаниях, проведенных на нескольких видах животных. Нельзя, например, утверждать, что 3,4-бензпирен является для человека столь же активным канцерогенным соединением, как для мыши. Хотя действие канцерогенных соединений изучалось на многих, видах животных, все же мы не имеем еще достаточных данных об этом действии на разные виды в эволюционном аспекте. В этом отношении очень ценны исследования с радиоактивными соединениями, проведенные Н. Н. Петровым с сотрудниками $(1956,1958)$ на обезьянах, результаты которых близки к данным из человеческой патологии.

В свете изложенных взглядов на этиологию опухолей среди многочисленных вопросов по проблеме опухолей можно выделить несколько направлений научных исследований, которые могут дать существенные результаты. К таким направлениям отно, сятся:

1) выявление новых канцерогенных агентов внешней среды;

2) развитие и расширение применения физических методов определения различных канцерогенных соединений;

3) изучение роли космических лучей в этиологии опухолей;

4) изучение связей наследственности предрасположения к опухолям с факторами внешней среды;

5) изучение комбинированного действия различных канцерогенных агентов (сильно действующих и слабых) между собой и с соединениями, обладающими коканцерогенным или потенцирующим, а также антиканцерогенным действием; 
6) выяснение действия различных чистых канцерогенных соединений в аспекте эволюционной патологии на разные виды животных, включая приматов, с конечной целью установить их возможное действие на человека и выяснить общебиологические закономерности канцерогенного действия.

Кроме того, исходя из положений, лежащих в основе нашей гипотезы, можно уже сейчас рекомендовать ряд профилактических мероприятий, в том числе: 1) максимальное уменьшение контакта с канцерогенными агентами внешней среды, особенно с продуктами термолиза топлив (в том числе с дымовыми выбросами), с радиоактивным излучением и другими известными канцерогенными агентами, применяя для этого все технические, гигиенические и медицинские средства предупреждения опухолей, 2) дополнение форм учета онкологических больных подробными данными о профессиональном анамнезе и о привычках, 3) учет при проведении профилактических мероприятий не столько содержания 3,4-бензпирена, который может служить лишь косвенным показателем канцерогенной активности для человека, сколько данных биологического опыта с сложными продуктами (неидентифицированными смесями), экспериментальные данные по которым почти полностью переносимы на человека.

\section{II. Патогенез}

Ответные механизмы организма, вызванные воздействием этиологического фактора внешней среды и составляющие сущность опухолевого процесса, чрезвычайно сложны. Патогенезу опухолей посвящено огромное количество исследований, и тем не менее многие вопросы еще не ясны. В рамках настоящего сообщения мы кратко рассмотрим лишь некоторые вопросы патогенеза опухолей. Большинство исследователей считает, что основные сдвиги пронсходят в одной или нескольких клетках [по P. Уиллису (R. Willis, 1953) - в поле клеток] и что влияние со стороны организма, составляющего среду для этих клеток, не является ведущим. Соглашаясь с этим положением, необходимо, однако, иметь в виду, что воздействие внешних причин на клетки не может быть понятс изолированно от взаимосвязей пораженных клеток с их окружением, которое может модифицировать, задерживать или нейтрализовать канцерогенное воздействие. Например известно, что ультрафиолетовые лучи не проникают глубоко в ткани организма, действуя лишь на поверхностные слои клеток кожи.

О механизме непосредственного действия канцерогенных агентов на клетки известно еще мало.

А. Граффи (A. Graffi, 1956) путем тщательных флуоресцентно-микроскопических исследований показал, что 3,4-бензпирен фиксируется на митохондриях клеток эпидермиса. Изучая морфологию этих клеточных структур под электронным микроскопом, удалось показать различные их изменения по сравнению с митохондриями гомологичных нормальных клеток. Дж. Миллер и Э. Миллер (1955) приводят обширный фактический материал о механизме действия аминоазосоединений на печень и выдвигают гипотезу, что в клетках печени белки связываются с азокрасителем (вернее, его производным), причем их синтез останавливается, а последующие поколения клеток, не содержащие этих белков, превращаются в опухолевые. Эти авторы считают, что как опухолеродные вирусы, так и химические канцерогенные вещества и лучистая энергия приводят к одному и тому же результату путем изменения белкового (ферментного) баланса клетки. Т. А. Корестелева $(1956,1959)$ показала, что при воздействии канцерогенного соединения изменяются антигенные свойства клеточных белков, что свидетельствует об их глубоком изменении и связывании белков с остатками канцерогена. Исходя современных представлений о характере наследственной субстанции как о нуклеопротеиде и учитывая, что опухолевые клетки представляют собой новую породу клеток с новыми, отличающимися от нормальных, наследственными свойствами, будет правильным говорить именно о нуклеопротеидах как о химическом субстрате, подвергающемся воздействию канцерогенных агентов. 
Точка зрения Б. И. Збарского (1947) о туморпротеине подвергается в последнее время критике. Так, А. Н. Паршин (1958) на основании биохимических исследований отрицает наличие в опухолях специфических белков (туморпротеинов) и считает вероятным, что изменение активности некоторых энзимов приводит к изменению количественного состава нуклеиновых кислот и белков в компонентах клетки, в результате чего наступает опухолевое превращение последней. В свете этих данных нуклеопротенды, как сложные комплексы нуклеиновых кислот и белков, можно рассматривать как носители опухолеродных свойств клеток. Несомненно, однако, что биохимическая сущность опухолевого превращения еще далеко не ясна, пто подтверждают также авторы одного из последних обзоров . С. Кнт и А. Гриффин (S. Kit, A. Griffin, 1958). Н. Н. Петров (1958), А. Граффи (1956), Ф. Бэрнет (F. Burnet, 1957), Дж. и Э. Миллеры (1955) и другие авторы считают, что изменения в белковых структурах клетки приводят к ее высвобождению из-под контроля организма. По современным представлениям (И. А. Уткин, 1956), в основе регуляции клеточного деления лежат обменные процессы, причем каковы механизмы этих процессов - неизвестно. И. А. Алов (1959) установил различия в нуклеиновом обмене нормальных и опухолевых клеток. Не подлежит сомнению, что регуляция и контроль над физиологическими и патологическими процессами роста и деления клеток (в том числе и опухолевого) осуществляется целостным организмом различными, тесно взаимосвязанными путями, из которых можно выделить в качестве основных четыре механизма: 1) нервная регуляция, 2) гормональная регуляция, 3) иммунологические реакции, 4) межклеточные взаимодействия.

Современные исследования во все возрастающей степени подчеркивают постепенность развития опухолей и лежащих в их основе изменений белковых комплексов клетки (А. Graffi, 1956; F. Seelich, 1956; H. Rusch, 1956 и др.). Постепенность опухолевого процесса настолько очевидна и подтверждена фактами, что даже сторонники мутационной теории вынуждены учитывать это и допускают последовательные мутации (F. Burnet, 1957), приводящие к постепенному развитию опухоли.

Ряд исследователей уже давно подчеркивал, что не следует резко отграничивать злокачественные опухоли от доброкачественных. Они являются, несомненно, звеньями одного опухолевого процесса, в основе которого лежит постепенное превращение опухолевого нуклеопротеида, который по различным причинам (продолжающееся канцерогенное или неспецифическое коканцерогенное воздействие, изменение контрольных и защитных механизмов организма) постепенно переходит в нуклеопротеид, характерный для злокачественного роста. По Л. М. Шабаду (1956), опухолевый процесс протекает всегда по единому типу, проходя в более или менее ясно выраженной форме следующие стадии: 1) диффузная неравномерная гиперплазия ткани; 2) отдельные первично-множественные пролифераты (без воспаления и рубцевания); 3 ) доброкачественная опухоль, возникающая иногда быстро, иногда исподволь из этих очагов пролиферата; 4) злокачественная опухоль, развивающаяся из доброкачественной. Развитие этих стадий происходит постепенно, причем некоторые из них подчас трудно установимы; нередко трудно провести четкую границу между доброкачественной и злокачественной стадиями. Наблюдения многочисленных авторов, а также наши исследования $(1954,1958)$ относительно канцерогенного действия сланцепродуктов отчетливо документируют такую постепенность развития опухолей. При этом следует подчеркнуть, что превращение доброкачественной опухоли в злокачественную происходит не во всей массе последней, а начинается с одного или нескольких участков опухолевой ткани. По-видимому, нет оснований для резкого противопоставления, как это делает И. Беренблюм (1956), вышеизложенной схемы постепенного развития опухоли данным о дремлющем опухолевом зачатке (A. Graffi, 1956), переходящем в зависимые от организма опухоли и дальше-в необратимые, биологически автономные (т. е. злокачественные) опухоли. В схему Л. М. Шабада также можно включить понятие дремлющего зачатка. Что же касается необратимости злокачественной опухоли, то имеются убедительные данные ряда авторов (Н. Н. Петров, 1958; W. Boyd, 1957; H. Hamperl, 1956; R. Willis, 1958 и др.) об обратном развитии даже злокачественных опухолей, не говоря уже о доброкачественных, остановка роста или обратное развитие которых 
представляют собой нередкое явление. Принципиально важное значение ңмеют также изученные Б. Г. Гольдиной (1949) факты, в частности то, что в метастазах злокачественных опухолей может наблюдаться тенденция к дифференциации. Все это свидетельствует о влиянии организма на развитие опухолевого очага и опровергает мутационную теорию. Опираясь на эти данные, следует считать, что безусловных предраковых состояний нет, т. е. все предшествующие раку стадии могут регрессировать. Вместе с тем бесспорно, что в случаях возникновения злокачественной опухоли предшествующие стадии обязательны, хотя они могут быть мало заметными или не определимы существующими методами диагностики. Что касается предрака в клинйческом понимании, то имеется ряд патологических процессов (А. И. Раков, 1958; Н. Н. Петров, 1958), часто или как правило предшествующих раку. В случаях, когда имеет место доброкачественная опухоль, можно говорить о жспецифическом» предраке; различные дистрофические процессы, рубцы и т. п. следует отнести к неспецифическим формам предрака, вызванным коканцерогенными или потенцирующими факторами. В обонх случаях, однако, отсутствует качество безусловности предракового процесса.

При развитии всех стадий опухолевого процесса возникают сложные взаимоотношения с регулирующими и защитными механизмами, играющими важную роль в развитии опухоли. Не имея возможности рассматривать эти взаимоотношения (в значительной части еще не изученные) подробнее, укажем лишь, что большое значение имеют нервная регуляция, гормональная система, иммунологические механизмы и межклеточные взаимодействия.

Много внимания уделялось защитной роли соединительной ткани (школа А. А. Богомольца; G. Domagk, 1956; W. Fischer, 1956 и др.).

Значительный интерес представляют обменные процессы, зависящие от питания (A. Tannenbaum, H. Silverstone, 1957). Большое значение в развитии опухолей имеет также возраст. P. Уиллис (R. Willis, 1953) считает, что в основе этого лежит не какая-то особая сенильность тканей, а фактор времени, требующегося для появления опухоли, вызванной внешними причинами.

Наиболее сложным является вопрос об эндогенном пронсхождении так называемых опухолевых вирусов.

Многочисленные эксперименты с перевиваемыми посредством бесклеточных фильтров опухолями - куриной саркомой Рауса, кроличьей папилломой Шопа и некоторыми другими - показали, что бесклеточный фильтрат содержит агент, передающий опухолевые свойства другому организму, как правило, очень близкому к донору. Этот агент имеет некоторые общие свойства с экзогенными внрусами, вызывающими инфекционные болезни: белковая природа, способность к размножению в определенных клетках, такие же размеры, как у некоторых инфекционных вирусов, и антигенные свойства. На этом основании ряд авторов причисляет этот агент к вирусам. Все указанные свойства, однако, присущи не только инфекционным вирусам, имеющим экзогенную природу, но и возникающнм в клетке нуклеопротеидным комплексам, являющимся основой опухолевого роста.

Работами А. Гирера и Г. Шрамма, Г. Френкель-Конрата и др. (см. А. С. Кривиский, 1958) доказано, что нукленновая кислота вируса табачной мозаики может передавать наследственную информацию. Известны также работы о трансформационных свойствах дезоксирибонуклеиновой кислоты. В свете этих данных и следует понимать «инфекционность» опухолевых нуклеопротендов, которая, однако, не делает их инфекІінонными живыми организмами.

При существующей ныне методике стало возможным выделить опухолевый нуклеопротеид у небольшого количества видов опухолей (около 20). По-видимому, в результате дальнейшего совершенствования методики станет возможным получение отделимого от клетки фактора у большего количества опухолей. Важно отметить специфичность опухолевого нуклеопротеида, о чем свидетельствует постоянство не только разных видов опухолей, но и клеточной породы одной опухоли. Последние данные Л. А. Зильбера (1958) о том, что агент Рауса вызывает у новорожденных кроликов фиброматозные узлы под кожей, весьма интересны и заслуживают дальнейшего ивучения с точки зрения изменчивости опухолевых нуклеопротеидов. В общих чертах можно 
себе представить, что опухолевые нуклеопротеиды разных опухолей отличаются в отношении одних наследственных кодов, определяющих видо- и тканеспецифичность опухоли, и являются в разной степени схожими по другим кодам, определяющим свойства опухолевого роста.

Понятие «вирус» не имеет еще на современном уровне знаний четкого определения. Основу этого определения составляют три отрицательных свойства: «вирус не видим в оптическом микроскопе, не задерживается в бактериальных фильтрах с определенным размером отверстий, не растет на искуссственных средах». Что касается первых двух свойств, то они полностью относятся и к крупным молекулам клетки. Тот факт, что нуклеопротеидные комплексы размножаются в живой клетке, также не подлежит никакому сомнению - это и является основой роста клеток и их размножения. В дочерних клетках все составные части протоплазмы имеются в удвоенном количестве. Из этого следует, что упомянутые отрицательные свойства не могут служить основой для перенесения на все нуклеопротеидные комплексы всех свойств инфекционных вирусов, трактуемых с позиций классического учения Л. Пастера об экзогенной природе возбудителей инфекционных заболеваний и с точки зрения привычных взглядов из области инфекционной патологии о непосредственной этиологической роли этих возбудителей.

Вопрос об эндогенном происхождении опухолеродных вирусоподобных агентов еще не решен окончательно.

Напомним выводы некоторых крупных специалистов-вирусологов. Так, К. Родс (1953) в введении к сборнику, специально посвященному роли вирусов в возникновении опухолей, утверждает: «Если путем введения бесклеточного экстракта какой-либо опухоли можно вызвать образование новой опухоли, то этого еще недостаточно для того, чтобы говорить о вирусном происхождении опухоли». Р. Гаррис (1956) в большой обзорной статье (254 проработанных труда) о свойствах агентов саркомы Рауса № 1 приходит к заключению, что происхождение (экзогенное или эндогенное) агента Рауса так же неясно, как и происхожденне любого другого вируса. Л. Дмоховский (1956) в обзоре о роли фактора молока в возникновении опухолей, составленном на основании 530 работ разных авторов, также указывает: «Таким образом, фактор молока, по многим свонм свойствам близкий к вирусам, можно также рассматривать как цитоплазматический агент». У. Стенли (1958) говорит, что «... мы нередко подходим очень близко к пограничной линии между экз̧огенным и эндогенным происхождением вирусовъ. Известный вирусолог Ф. Бэрнет (F. Burnet, 1955), перечисляя особенности опухолеродных вирусов, указывает: «...все факты согласуются с тем, чего можно было бы ожидать, если они имели бы непосредственное или относительно недавнее эндогенное происхождение». В таком же смысле высказываются Р. Дёрр (R. Doerr, 1944), автор одного из первых крупных обзоров об опухолевых вирусах O. Томсен (О. Thomsen, 1939) и ряд других вирусологов. В последнее время отчетливо выявляется тенденция рассматривать опухолеродные вирусоподобные агенты, бактериофаги и некоторые растительные вирусы как эндогенные образования в отличие от других вирусов, имеющих экзогенную природу, Что касается растительных вирусов, то Ф. Боуден и Н. Пири (1956) на основании большого фактического материала указывают, что нет резкой разницы между размножением вируса и синтезом нуклеиновой кислоты. Об эндогенном происхождении растительных вирусов говорит также К. С. Сухов (1951), а фактический материал, полученный Б. Х. Нурмисте (1958) с вирусами картофеля, также допускает эндогенное происхождение вируса.

Относительно бактериофагов также имеются данные, что они не являются паразитами в обычном смысле (P. Nicolle, 1957); об особом типе размножения фагов большой фактический материал приведен у А. С. Кривиского (1958). Существенное значение имеют опыты с фагами, меченными радиоактивными изотопами, которые показали, что подавляющее большинство фаговых частиц не имеет составных частей родительского фага, а синтезируется из белков бактериальной клетки. А. Львов (1956) дает бактернофагу такое определение: жТеоретически это есть специфический, способный к 
размножению нуклеопротеид или молекула, которая была, есть или может стать инфекционной или патогеннойљ. Глубокое изучение лизогении привело ряд крупных микробиологов (Бордэ, Феликс и др.) к убеждению об эндогенном происхождении фага (Wilson, Miles, 1955, стр. 423). Известные опыты У. Стенли (1958) по кристаллизации вируса табачной мозаики также доказывают, что это химическая молекула; в таком же смысле следует понимать многочисленные опыты по реконструкции вирусов (сводка А. С. Кривиского, 1958) и по изучению молекулы рибонукленновой кислоты, передающей инфекционные свойства вируса табачной мозаики (A. Gierer, 1958). Тرактовка опухолевых вирусоподобных агентов как возникших эндогенно нуклеопротеидов позволяет объединить в единую концепцию все факты не только вирусологических исследований, но и патологии и клиники. Обширный экспериментальный материал, полученный при изучении канцерогенных агентов, может в таком случае также быть легко объяснен.

Исходя из этого, следует, разрабатывая классификацию вирусов, в понятие ๔вирус» включать только экзогенные вирусы, а саморепродуцирующиеся нуклеопрогеиды (в том числе опухолевые протеиды, некоторые растительные вирусы и фаги) необходимо рассматривать отдельно, учитывая их эндогенную природу, и не наделять их путем необоснованного обобщения всеми свойствами инфекционных живых организмов. При этом инфекционность, понятие о которой следует уточнить в свете современных данных, не может быть четкой основой для классификации. Если за истинными вирусами следует, по-видимому, признавать их экзогенную природу, хотя относительно их филогенеза имеются противоречивые взгляды (R. Doerr, 1944; Л. А. Зильбер, 1956 и др.), то опухолевые нуклеопротеиды являются эндогенными продуктами нормальных клеток, возникшими в результате воздействия внешних причин и приобретающими на разных стадиях развития разную степень отделимости от клеток, становясь условно экзогенными. По-видимому, эти эндогенные саморепродуцирующиеся нуклеопротеиды представляют собой сложные жживые молекулы», стоящие на границе с живыми организмами (У. Стенли, 1958). Выражение жживые молекулы» следует понимать в том смысле, что эти молекулы могут передавать ряд особенностей жизненных функций другим молекулам, причем они лишены ряда жизненно необходимых функций, обеспечивающих самостоятельные обменные процессы. Как указывает А. С. Кривиский (1958), вирусы на определенных этапах своего развития вступают с клетками в столь тесные взаимоотношения, которые неизвестны ни в одном случае паразитизма. В этой связи заслуживают внимания и дальнейшего изучения отношения вирусов и наследственных частиц клетки. По мнению У. Стенли (1958), вирусы в определенных случаях выступают как гены, а гены как вирусы. Исходя из этого, У. Стенли даже ставит вопрос о рациональности пересмотра определения вируса, включнв в него нуклеиновую кнслоту и, возможно, воспроизводящиеся структуры, неинфекционные в обычном смысле (не покидающие клетку в течение ряда поколеннй и воспроизводящиеся только во время деления клетки). Л'Эритье (L'Heritier, 1958) прямо указывает, что нет возможности провести ясную черту между вирусами и агентами, считающимися ответственными за экстрахромозомальную наследственность. Эти агенты (плазмагены) невозможно, однако, идентифицировать и с инфекционными микроорганизмами. Весьма сложной является также проблема фактора молока, который также можно рассматривать как цитоплазматический агент наследственности (Л. Дмоховский, 1956).

Против того, что опухоли вызываются вирусами, идентичными возбудителям вирусных инфекций, свидетельствует и характер роста опухоли, которая, по всеобщему признанию, растет путем размножения клеток, исходя из одной клетки (или нескольких), а окружающие клетки не превращаются в опухолевые. Инфекционные вирусы поражают организм, как правило, другим образом - пораженные клетки разрушаются, высвободившийся из них размножившийся вирус попадает в окружающие клетки, в кровь, лимфу; в нервные стволы и т. д.

Несомненный интерес представляют работы А. Д. Тимофеевского (1954) о злокачественном превращении культуры тканей при воздействии вирусов и канцерогенных 
соединений. При этом следует отметить, что, взятые в отдельности, эти агенты не вызывали озлокачествления. В таком же направлении синергизма причинного фактора и вирусоподобного агента следует понимать и данные П. Рауса и У. Фридевальда (P. Rous, W. Friedewald, 1944) о том, что кроличьн вирусные папилломы превращаются значительно быстрее в рак при предварительном воздействии на кожу канцерогенной смолы. По-видимому, аналогичное явление имеет место и при переносе растительных вирусов здоровому растению при тех же экологических условиях, а также при получении лизогенных штаммов бактернй путем «инфицирования» фагом.

Нет сомнения, что основной вопрос о возможности эндогенного происхождения вирусоподобного агента, который мы пытаемся отождествить с присущим каждой опухоли специфическим опухолевым нуклеопротеидом, еще далеко не ясен. Все же уже сейчас ясно, что отсутствуют доказательства для признания инфекционного вируса универсальной непременной причиной опухолей (Н. Н. Петров, 1958). Полученные в последнее время иммунологические данные об аутоантигенах, возникающих в клетках как при введении бесклеточного фильтрата (Л. А. Зильбер, 1956), так и при воздействии канцерогенного соединения (Т. А. Корестелева, 1957, 1959), также подтверждают это.

В заключение подичеркнем, что рассмотрение опухолевого процесса как единого процесса можно понимать только в смысле общей тенденции к нерегулируемому, Сезудержному росту. Механизмы же развития различных опухолей могут быть весьма различными в зависимости от различных причин, порождающих их. Опухолевые нуклеопротеиды специфичны для каждого конкретного вида опухолей. Учитывая это, нет оснований рассчитывать на единое средство лечения опухолей.

На основании вышеизложенных взглядов можно сформулировать некоторые целесообразные направления дальнейших научных исследований:

1) дальнейшие вирусологические исследования с целью составления классификации вирусов, выяснения их филогенеза и дифференциации их от эндогенных вирусоподобных агентов, стоящих на грани с живыми организмами;

2) создание классификации опухолей на основании типов специфических изменений нуклеопротеидов при разных видах опухолей;

3) углубление иммунобиологических и биохимических исследований для обоснования способов ранней диагностики и ранней терапии предопухолевых изменений;

4) постановка широких исследований для выяснения контролирующих и регулирующих механизмов организма как противоопухолевых факторов, в первую очередь нервной системы, гормональных и иммунологических механизмов, с целью управлять ими в необходимом направлении;

5) изучение роли соединительной ткани в противоопухолевых защитных механизмах организма;

6) изучение закономерностей нормального и опухолевого роста и превращения нуклеопротеидов путем применения современных методов физики и химии.

\section{Л ИТЕРАТ У Р А}

А лов И. А., 1959. Вопр. онкологии, 5 I, 7-13. - Бед жер Г. (Badger, G. М.), 1956. В кн. Успехи в изучении рака, т. II, Изд. иностр. лит., М., 58-113. - Бе р енблю м И. (Berenblum, I.), 1956. В кн. Успехи в узучении рака, т. II, Изд. иностр. лит., М., 9-57. - Б ог о в с к и й П. А., 1954. Фармакол. и токсикология, $17,3,56-$ 59. - Б ого в с ки й П. А., 1958. В кн. Вопросы гигиены труда в сланцевой промышленности, сб. 3, Таллин, 172-185. - Бо уде н Ф., Пи ри Н. (Bawden, F. С., Pirie, N. W.), 1956. В кн. Природа размножения вирусов, Изд. иностр. лит., М., 36-66. - Г а р д н е р В. (Gardner, W. U.), 1955. В кн. Успехи в изучении рака, т. I, Изд. иностр. лит., М., 122-192. - Г а р р и с Р. (Harris, R. I. С.), 1955. В кн. Успехи 
в изучении рака, т. I, Изд. иностр. лит., М., 270-313. - Г л а з у н о в М. Ф., 1958. В кн. Руководство по общей онкологии, гл. IV, M., 53-71. - Г ольдин а Б. Г., 1949. Архив патологии, 11, 3, 65-69. - Г р и ц ю е Л. А., 1956. Вопр. онкологии, $2,6,671-678$. - Д а в ы д о в к и й И. В., 1956. Патологическая анатомия и патогенез болезней человека, Изд. III, т. I, M. - Д м ох в в к и й J. (Dmochowski L.), 1955. В.кн. Успехи в изучении рака, т. І, Изд. иностр. лит., М., 193-269. Д олл P. (Doll, R.), 1957. В кн. Успехи в изучении рака, т. III, Изд. иностр. лит., M., $11-66$. - Жд а н в В. М., 1958. Вестн. АМН СССР, 13, 11, 73-76. - Ж у к вВережников Н. Н., М ай ки й И. Н., Калиниченко Л. А., 1955. Успехи соврем. биол., $39,2,245-252$. - 3 б а р с к и й Б. И., 1947. Врачебн. дело, 27, 2-3, 97-104. - 3 дрод о в ки й П. Ф., 1959. Вестн. АМН СССР, 14, 2, 9-15. 3 и ль бе р Л. А,, 1954. Клинич. медицина, 32, 3, 9-16. - 3 и ль бе р Л. А., 1956. Здравоохр. Қазахстана, 10, 3-7. - 3 и льбе р Л. А., 1956. Учение о вирусах, М. 3 ильбе р Л. А., 1958. Патологич. физиол. и эксперим. терапия, 2, 3, 3-9. 3 и ль бер Л. А., 1959. Вестн. АМН СССР, 14, 2, 15-21. - К оре с телев а Т. А., 1957. Вопр. онкологии, 3, 5, 641-652. - К ор ест ел е а Т. А., 1959. Вопр. онкологии, $5,1,22-28$. - К р и в и с к й А. С., 1958. Успехи соврем. бнол., 45, 3, 286-312. Л ак ассань А., Бы у-Х ой Н., Додель Р., 3 а й дел а $\Phi$. (Lacassagne, A., Buu-Hoï, N. P., Daudel, R., Zajdela, F.), 1958. В кн. Успехи в изучении рака, т. IV, Изд. иностр. лит., М., 350-406. - Л а р и о о в Л. Ф., 1955. Успехи соврем. биол., $39,2,196-211$. - Л е й т е с Ф. Л., 1958. Вопр. онкол., 4, 5, 629-635. - Л о у Л. (Law, L. W.), 1956. В кн. Успехи в изучении рака, т. II, Изд. иностр. лит., М., 216293. - Л в в о в A., (Lwoff, А.), 1956. В кн. Природа размножения вирусов, Изд. иностр. лит., М., 186-216. - М и л л е р, Дж., М и л л ер Э. (Miller, J. A., Miller, E. С.), 1955. В кн. Успехи в изучении рака, т. I, Изд. иностр. лит., М., 7-71. Н ей м а Н. М., 1958. Патологич. физиол. и экспер. терапия, 2, 3, 10-13. Н у р м и те Б. Х., 1958. Оценка методов борьбы с вырождением картофеля. Материалы конференции по вопросам семеноводства картофеля, Изд. Мин. сельск. хоз. СССР, M. - О бе р ле н Ш., Г ер е н М. (Oberling, C., Guérin, M.), 1956. В кн. Успехи в изучении рака, т. ІІ, Изд. иностр. лит., М., $294-373$. - П а рш и н А. Н., 1958. В кн. Руководство по общей онкологии, гл. V, $72-87$, M. - Пет р о в Н. Н., 1954. Очерк материалов для выработки теории опухолевого роста, Л. - П е р о в Н. Н., 1958. Руководство по общей онкологии (под ред. Н. Н. Петрова). Главы I-III, VII - IX, XI и XVI, Л. - Пет ро в Н. Н., Ш а б ад Л. М., 1958. В кн. Руководство по общей онкологии, гл. VI, 88-101, М. - П о г с ян ц Е. Е., 1956. Вестн. АМН СССР, 11, 4,9-21. - Преснов М. А., Пригожина Е. Л., Светухин а О. В., Тр апезников Н. Н., 1958. Вестн. АМН СССР, 13, 7, 78-88. П ульм ан А., Пульм ан Б. (Pullman, A., Pullman, В.), 1957. В кн. Успехи в изучении рака, т. ІІІ, Изд. иностр. лит., М., 305-362. - Р а к о В А. И., 1958. В кн. Руководство по общей онкологии, гл. Х, М., 222-242. - Р о д с К. (Rhoads, С.), 1953. В кн. Роль вирусов в возникновении опухолей, Изд. иностр. лит., М., $19-20$. С те нли У. (Stanley, W. M.), 1958. Вирусы и рак, Изд. «Знание» (серия VIII, вып. I, № 2), М. - С у х о в К. С., 1951. В сб. Фнлософские вопросы современной биологии, Изд. АН СССР, М., 335-345. - С ы и н А. Н., 3 и л ь 6 е р Л. А., Р я 3 а н о В.В. А., Ш а б а д Л. М., 1956. ХІІІ Всесоюзный съезд гигиенистов, эпидемиологов, микробиологов и инфекционистов. Тезисы докладов, кн. I, M., $14-15 .-$ Т и о фе евс к и й А. Д., 1954. Архив патологин, 16, 3, 13-23. - У т к н И. А., 1956. Вестн. АМН СССР, 11, 4, 22-31. - Ш а б а д Л. М., 1947. Очерки экспериментальной онкологии, М.-JI. - Ш а 6 а д Л. М., 1956. В кн. 30 лет деятельности Института онкологии АМН СССР 1926-1956, Л., 10-16. - Ш а б а д Л. М., 1958. В кн. Руководство по общей онкологии, М., 175-176.

Arcos, M., A r cos, J., 1958. Arzneimittel-Forschung, 8, 8, 486-488. - B a u e r, K. H., 1949. Das Krebsproblem, Springer B-G-H. - B o y d, W., 1957. Canadian Cancer Conference, 2, Acad. Press, New York, 354-360. - B r ow n, J. R., Th or n t o n, J. L., 1957. Brit. Journ. Industr. Med, 14, 1, 68-70. - B u rnet, F. M., 1955. Principles of Animal Virology, Acad. Press, New York. - B urnet, [F.] M, 1957. Brit. Med. Journ., Vol. 1, No. 5022, 779-786; No. 5023, 841-847. - B ut en and t, A., D a n ne n ber g, H., 1956. Handb. d. allgem. Pathol., B. VI, 3. Teil, Springer B-G-H, 107-241. - B ü c h n e r, F., 1956. Allgemeine Pathologie, Urban u. Schwarzenberg, München-Berlin. - D o e r r, R., 1944. Handb. d. Virustorschung, 1. Ergänzungsband, Springer, Wien, 1-87. D o m a g k, G., 1956. Handb. d. allgem. Pathol., B. VI, 3. Teil, Springer B-G-H, 242367. - D r uckre y, H., 1954. Strahlentherapie, 93, 2, 165-180. - F is her, R. E. W., 1953. Arch. Industr. Hyg. a. Occup. Med., 7, 1, 12-18. - F is c h e r, W., 1956. Handb. d. allgem. Pathol., B. VI, 3. Teil, Springer B-G-H, 368-442. - Gi e r e r, A., 1958. Ztschr. f. Naturforsch., B, 136, 8, 477-484. - Gr a f f i, A., 1956. Deutsche Akad. d. Wissensch. zu Berlin 1946-1956, Akad.-Verl. Berlin, 249-272. - H a d d o w, A., 1957. Canadian Cancer Conference, Vol. 2, Acad. Press, New York, 351-374. - H a m p e r 1, H., 1956. Handb. d. allgem. Pathol, B. VI, 3. Teil, Springer B-G-H, 18-106. - H ort o n, A. W., D e nm a n, D. T., Tros set, R. P., 1957. Cancer Research, 17, 8, 758-766. - H u e per, W. C., 
1957. Cancer, Vol. 1, Part I, Ch. 11, London, 404-496. - Ken n a w a y, E. L., 1955. Brit. Med. Journ., Vol. 1, No. 4922, $1107-1110$. - Ke n n a w a y, E. L., 1957. Cancer, Vol. 1, Part 1, Ch. 3, London, 24-31. - K it, S., G r iff i n, A. C., 1958. Cancer Research, 18, 6, 621-656. - Kot i n, P., 1958. Cancer Research, 18, 1, 1-3. - Kö r b ler, J., Fr a n k, P., 1957. Arch. Geschwulstforsch., 10, 2, 168-178. - L' Her it i e r, Ph., 1958. Advances in Virus Research, Vol. V. New York, 195-245. - N e l s o n, H. M., 1955. Philippine Med. World, 16, 10, 675-685; Реферат: Реф. журн. Бнология, 10, 43456, 1957. Ni colle, P., 1957. Rev. pathol, gén. et physiol. clin., 57, № 692, 1501-1516; Реферат: Реф. журн. Биология, 13, 57319, 1958. - Not h d u r f t, H., 1948. Ztschr. Krebsiorsch., 56, 2. 176-204. - R ous, P.. Fr i e d ew a ld, W. F., 1944. Journ. Exper. Med., 79, 511-538; Цит. по Stanley, W. M., 1957. - Rusch, H. P., 1956. Currents in Biochemical Research New York-London, 675-697. - S chmi d , F., 1953. Ober die Virustheorie-Induktionstheorie der Krebsentstehung. Eine Arbeitshypothese. Beitr. zur Krebsforschung, B. 3. Steinkopff, Dresden-Leipzig. - S ch m i d t, F., 1956. Deutsche Akad. d. Wissenschaiten 1946-1956, Berlin, 273-296. - S e e l i c h, F., 1956. Wiener klin. Wochenschr., 68. 52, 1009-1013. - S m it h, W. E., 1952. Arch. Industr. Hyg. a. Occ. Med. 5, 3, 243263. - St anley, W. M., 1957. Krebsarzt, 12, 6, 307-320. - St e in er, P. E., 1953. Arch. Path., 55, 3, 227-244. - T a n nen b u m, A., S i lverstone, H., 1957. Cancer, Vol. 1, Part I, Ch. 9, London, 306-334. Th o m s e n, O., 1939. Handb. d. Virusforsch., 2. Hälfte, Springer, Wien, 994-1105. - Willi s, R. A., 1953. Pathology of Tumours, 2nd Ed., London. - Wils o n, G. S., Mile s, A. A., 1955. Topley and Wilson's Principles of Bacteriology and Immunity, Vol. I, 4th Ed., London. - Y a m a g i w a, K., I t ch i k a w a, K., 1917. Gann, 11, 19-26.

\title{
Ннститут экспериментальной и клинической медицинь Поступнла в редакцию Академии наук Эстонской ССР \\ 25 II 1959
}

\section{KASVAJATE ETIOLOOGIA JA PATOGENEESI UHTNE TÖOHUPOTEES}

\author{
P. Bogovski, \\ meditsiniteaduste kandidaat
}

Resümee

Toetudes uuematele seisukohtadele esitatakse artiklis polüetioloogilis-biokeemiline tööhüpotees kasvajate etioloogia ja patogeneesi kohta. Kasvajaid põhjustavate väliskeskkonna teguritena vaadeldakse peamiselt keemilisi ja füüsikalisi tegureid; väheste bioloogiliste tegurite seas käsitletakse viirusetaolisi agenseid kui tingimusi eksogeensetena esinevaid rakusisese tekkega nukleoproteiide. Oluline on arvesse vōtta mitmesuguste eksogeensete pōhjuste (iseäranis nōrkade kantserogeensete) ja kokantserogeensete ning potentseerivate tegurite koostoime tähendust. Kasvajate levik ei toimu epidemioloogia seaduste alusel, mis kōneleb nakkusliku kasvajatekitaja vastu. Samal ajal tõestab mōnede kasvajaliikide likvideerimine teatavate väliste tegurite kõrvaldamisega nende kasvajate pōhjuslikku seost vastavate teguritega. Esitatakse mõned olulisemad teadusliku uurimise suunad kasvajate etioloogia alal ja mōned profülaktilised üritused, mis tulenevad esitatud seisukohtadest.

Kasvajate patogeneesi olulisema küsimusena käsitletakse kasvajalise nukleoproteiidi järkjärgulist kujunemist, kusjuures on esitatud seisukoht, et mörel juhul vōib isee nukleoproteiid olla rakust eraldatav, meenutades nakkuslikke viiruseid mōne omaduse poolest. Rōhutatakse organismi kontrollmehhanismide osatähtsust ja kasvajate järkjärgulist arenemist, mis vōib toimuda organismist olenevalt ka taandarenemise suunas. Toetudes kirjanduses leiduvatele seisukohtadele ja faktile, et viiruse mõistet õigustamatult üldistatakse, püütakse pōhjendada kasvajaliste viirusetaoliste agensite endogeense tekke hüpoteesi õigustatust. Peale selle tõstetakse artiklis esile olulisemaid kasvajate patogeneesi uurimise suundi. 


\title{
EINE EINHEITLICHE ARBEITSHYPOTHESE DER ATIOLOGIE UND PATHOGENESE DER GESCHWULSTE
}

\author{
P. Bogowsky
}

\section{Zusammenfassung}

Auf Grund der neueren Standpunkte wird im Artikel eine polyätiologisch-biochemische Arbeitshypothese der Ätiologie und Pathogenese der Geschwülste dargelegt. Als Geschwülste verursachende Umweltfaktoren werden hauptsächlich chemische und physikalische Noxen angesehen; unter den wenigen biologischen Faktoren werden die virusähnlichen Agenzien als bedingt exogen vorkommende intracellulär entstandene Nukleoproteide betrachtet. Es ist wichtig, die Bedeutung der Zusammenwirkung mehrerer exogener Unsachen (besonders der schwach kanzerogenen), sowie der kokanzerogenen und potenzierenden Faktoren zu berücksichtigen. Die Verbreitung der Geschwülste erfolgt nicht den Gesetzen der Epidemiologie gemäss, was gegen einen infektiösen Geschwulsterreger spricht. Auch beweist die Liquidation mancher Geschwulstarten mittels Beseitigung bestimmter Aussenfaktoren den kausalen Zusammenhang dieser Geschwülste mit den entsprechenden Faktoren. Es werden einige wichtigere Richtungen der wissenschaftlichen Forschung auf dem Gebiete der Ätiologie der Geschwülste angeführt, gleichwie einige prophylaktische Massnahmen, die sich aus den vorgebrachten Ansichten ergeben.

Als eine bedeutende Frage der Pathogenese der Geschwülste wird die allmähliche (graduelle) Bildung des Geschwulstnukleoproteids erörtert, wobei die Ansicht vertreten wird, dass dieses Nukleoproteid in einigen Fällen von der Zelle abgetrennt werden kann, wobei manche seine Eigenschaften denen der infektiösen Viren ähneln. Betont wird im Artikel die Rolle der Kontrollmechanismen des Organismus, sowie die stufenweise Entwicklung der Geschwülste, die infolge der Gegenwirkung des Organismus auch in der Richtung der Rückbildung stattfinden kann.

Auf Grund von Literaturangaben und der Tatsache, dass der Begriff «Virus» unberechtigterweise verallgemeinert wird, versucht man die Hypothese der endogenen Entstehung virusartiger Agenzien der Geschwülste zu begründen. Es werden auch die wichtigeren Richtungen der wissenschaftlichen Forschung auf dem Gebiete der Pathogenese der Geschwülste beleuchtet.

Institut für experimentelle und klinische Medizin der Akademie der Wissenschaften der Estnischen SSR
Eingegangen

am 25. Febr. 1959 